\title{
Análise de processos de degradação acelerada em laboratório para estudo da durabilidade de peças cerâmicas vermelhas incorporadas com resíduo de granito
}

\section{(Analysis of accelerated process of degradation for durability research of red ceramic samples incorporated with granite waste)}

\author{
G. C. Xavier, F. Saboya, P. C. A. Maia, J. Alexandre \\ Laboratório de Engenharia Civil - LECIV, Universidade Estadual do Norte Fluminense \\ Av. Alberto Lamego 2000, Horto, Campos dos Goytacazes, RJ 28013-600 \\ gxavier@uenf.br,saboya@uenf.br,maia@uenf.br
}

\begin{abstract}
Resumo
Este trabalho apresenta resultados sobre durabilidade de artefatos cerâmicos vermelhos incorporados com resíduo de granito, produzidos no pólo cerâmico de Campos dos Goytacazes-RJ. Inicialmente, para avaliação e análise do desempenho dos cerâmicos, são apresentados resultados da caracterização da massa argilosa e do resíduo de granito e, também, os efeitos da degradação do cerâmico obtido com a adição do resíduo de granito na massa argilosa. A massa argilosa foi coletada numa Indústria Cerâmica da região de Campos dos Goytacazes, RJ, e o rejeito é oriundo da região de Cachoeiro de Itapemirim, ES. As misturas foram feitas adicionando-se $0 \%, 5 \%$ e $10 \%$ de rejeito, em peso, até homogeneização da massa argilosa para posterior obtenção de corpos de prova prismáticos. Os corpos de prova foram submetidos a secagem e queima a $500{ }^{\circ} \mathrm{C}, 700{ }^{\circ} \mathrm{C}$ e $900{ }^{\circ} \mathrm{C}$. De um lote de amostras foram obtidas as propriedades tecnológicas. Em outro lote, as amostras foram levadas ao equipamento de degradação e a ciclos de umidade para promover a alteração do cerâmico. Foram consideradas até $1500 \mathrm{~h}$ de lixiviação contínua no equipamento, e 50 e 150 de ciclos de umidade. Através da microscopia eletrônica de varredura foram observadas as modificações na microestrutura do material antes e depois da degradação. Os resultados mostram que certa quantidade de incorporação de resíduo tem influência considerável na evolução da degradação. Além disto, são notadas maiores resistências à degradação no material incorporado.
\end{abstract}

Palavras-chave: cerâmica vermelha, resíduo de granito, degradação.

Abstract

This paper shows results obtained from durability tests on red ceramic bodies incorporated with granite waste, aiming to assess the long time behavior of the ceramic materials produced in Campos of Goytacazes, RJ. Results from characterization of the ceramic raw material are shown to clarify the influence on the degradation (weathering) process as well as the influence of the granite waste content. The raw material was obtained from a ceramic industry in Campos dos Goytacazes, RJ, and the granite waste by-product is from a decorative rock industry in Cachoeiro do Itapemirim, ES. Mixing was obtained using 0\%, 5\% and 10\% of waste, in weight, homogenized and molded in prismatic specimens. These specimens were led to dry and fired at $500{ }^{\circ} \mathrm{C}, 700{ }^{\circ} \mathrm{C}$ and $900{ }^{\circ} \mathrm{C}$, in an oven. Two lots of samples were separated, being the first one used to the assessment of technological properties and the other to perform the weathering tests. In the lixiviation equipment, the samples were tested for $1500 \mathrm{~h}$ with intervals of 50 to $150 \mathrm{cycles}$ for allowing them to dry and to soak. Changes in microstructure of the samples were observed after the weathering tests using scanning electron microscope. The results have shown that the granite waste incorporation in the raw material dramatically changes the weathering process.

Keywords: red ceramic, granite waste, degradation.

\section{INTRODUÇÃO}

A produção de rochas ornamentais gera cerca de 150.000 ton de resíduo de granito/mês [1] no município de Cachoeiro do Itapemirim, ES, em função da operação de mais de 500 indústrias de extração, desdobramento e beneficiamento de rochas, com aproximadamente 900 teares, geradores de resíduos. Entretanto, existe grande potencial de utilização do resíduo de mármore e granito introduzidos na massa cerâmica para fabricação de tijolos, blocos cerâmicos estruturais e outros produtos cerâmicos, principalmente quando avaliado sob condições de desgaste [2].

Algumas das indústrias cerâmicas de Campos dos Goytacazes, RJ, acenam com a possibilidade de uso do rejeito de granito para introdução na massa cerâmica da região visando obter produtos de melhor qualidade. Destacase que inúmeras pesquisas mostram melhorias nos produtos cerâmicos com a incorporação de resíduo de granito [3-6].

Foi ressaltado o uso do rejeito de granito em formulações em cerâmica vermelha para fabricação de telhas, produto mais 
nobre e de maior valor agregado [7]. Neste caso, observase que ocorre redução da retração do material e elevação da resistência mecânica da peça com certa quantidade de rejeito, que favorece a formação de fase líquida na queima, características importantes para o produto.

Os materiais atualmente produzidos no pólo cerâmico de Campos, RJ, apresentam alguns problemas quando expostos às condições climáticas locais. Isso ocorre nos cerâmicos sem proteção mecânica externa das paredes e em telhados com pequena declividade. Os principais problemas observados são: alvenaria de vedação deteriorada, telhas com gotejamentos, trincas aparentes, etc. [8]. Destaca-se que o município de Campos dos Goytacazes gera cerca de $35 \%$ da produção de cerâmica vermelha do Estado do Rio de Janeiro, contando com aproximadamente 100 indústrias cerâmicas, produzindo 100 milhões de peças/mês [9]. Este aspecto justifica a implementação de estudos no sentido de se obter materiais mais duráveis e resistentes para a construção civil.

Este trabalho visa o estudo da aplicação de uma massa argilosa e um resíduo de granito para composição de peças cerâmicas com melhores características físicas e de durabilidade. Foi feito um estudo experimental utilizando-se processos de degradação acelerada em laboratório a fim de se avaliar a influência da introdução do resíduo de granito na massa argilosa nas características físicas de durabilidade do material. A preparação das massas e dos corpos de prova foi feita sob condições controladas em laboratório e simula a produção dos seguintes materiais cerâmicos na região: blocos furados, blocos estruturais e telhas.

\section{MATERIAIS E MÉTODOS}

Os materiais utilizados foram a massa argilosa coletada na A.C. Cerâmica Ind. Com. Ltda., município de Campos dos Goytacazes, RJ, e o resíduo do corte dos blocos de granito da MARCEL Mármore Comércio e Exportação Ltda., Cachoeiro do Itapemirim, ES.

A programação experimental buscou a determinação das características física, mineralógica, química, e ambiental do resíduo e da massa argilosa. O comportamento térmico do pó e as propriedades tecnológicas das amostras, bem como, das características de durabilidade do produto cerâmico, foram realizados após misturas de resíduo na massa de conformação de cerâmica vermelha. Os materiais utilizados foram processados em peneira $200(0,074 \mathrm{~mm})$ e levados para as caracterizações mineralógica, química, térmica e ambiental. Na caracterização física foi determinada à distribuição do tamanho de partículas dos materiais, via úmido por peneiramento e sedimentação gravimétrica, segundo a norma ABNT [10]. Para a caracterização mineralógica, os materiais foram analisados em difratômetro de raios $\mathrm{X}$ Siemens D-5000 equipado com espelho Goebel para feixe paralelo. A varredura $2 \theta$ foi entre $5^{\circ}$ e $80^{\circ}$.

Para análise química semiquantitativa, os materiais foram secos em estufa a $110^{\circ} \mathrm{C}$ por $24 \mathrm{~h}$. A composição química das matérias-primas foi obtida por em espectrômetro de fluorescência de raios X Philips PW2400 com tubo de Rh.
Na caracterização térmica, o método utilizado foi a análise térmica diferencial. Utilizou-se $30 \mathrm{mg}$ de cada amostra, em atmosfera de nitrogênio, taxa de $10^{\circ} \mathrm{C} / \mathrm{min}$ até $1020^{\circ} \mathrm{C}$.

Para identificar a presença de metais pesados na amostra de rejeito foram feitos testes de lixiviação e solubilização [1114]. Os equipamentos utilizados foram turbidímetro Micronal B250, espectrofotômetro UV-Visível Shimadzu mini 1240, fotômetro de chama Micronal B261, espectrofotometria de absorção atômica com chama de ar/acetileno Perkin Elmer Analyst 300 e espectrometria de emissão atômica por plasma indutivamente acoplado (ICP/OES) Perkin Elmer.

As amostras para os ensaios tecnológicos foram preparadas com misturas de massa argilosa e adições de $0 \%, 5 \%$ e $10 \%$ de resíduo da massa da amostra inicial, denominadas $0 \mathrm{R}, 5 \mathrm{R}$ e $10 \mathrm{R}$, respectivamente. A massa argilosa e o resíduo foram passados na peneira $20(0,85 \mathrm{~mm})$.

As misturas foram feitas com os materiais inicialmente secos em estufa a $110^{\circ} \mathrm{C}$ por $24 \mathrm{~h}$. A umidade de extrusão utilizada foi calculada através da equação (A):

$$
\mathrm{W}_{\mathrm{ext}}=\frac{\mathrm{LL}}{2}+2 \%
$$

onde LL é o limite de liquidez que define o teor de umidade limite para o qual o material se torna completamente fluido.

Após a mistura, as amostras foram levadas para dupla laminação e extrusão em laboratório. As amostras foram moldadas com dimensões de $11,0 \times 2,7 \times 1,7 \mathrm{~cm}^{3}$. Os processos de secagem dos corpos de prova foram feitos em estufa a $110^{\circ} \mathrm{C}$. A queima foi feita a $500{ }^{\circ} \mathrm{C}, 700{ }^{\circ} \mathrm{C}$ e $900{ }^{\circ} \mathrm{C}$ em forno mufla eletrônico, com taxa de aquecimento $5{ }^{\circ} \mathrm{C} /$ min e patamar de queima de $3 \mathrm{~h}$ para garantir a queima mais homogênea. $\mathrm{O}$ resfriamento ocorreu naturalmente. Essas temperaturas de queima representam aquelas utilizadas pela indústria cerâmica de Campos dos Goytacazes.

Para a avaliação da degradação do material foram utilizados dois diferentes procedimentos de ensaio de laboratório: lixiviação contínua e ciclos de umidade. A lixiviação contínua foi realizada em equipamento de degradação (Fig. 1), que possibilita controlar períodos de variação de temperatura (água quente a $70{ }^{\circ} \mathrm{C}$ e água fria a $30^{\circ} \mathrm{C}$ ) e de precipitação da solução de lixiviação. Neste equipamento utiliza-se água destilada como solução de lixiviação a fim de garantir a padronização do ensaio. Este ensaio de laboratório é considerado o que mais se aproxima das condições climáticas que degradam os cerâmicos vermelhos no campo [15]. Os tempos utilizados no equipamento de degradação foram $300 \mathrm{~h}, 658 \mathrm{~h}$ e $1500 \mathrm{~h}$ para cada tipo de amostra.

O ensaio de ciclos de umidade que simula as variações sazonais de variação de umidade e temperatura do material no campo é freqüentemente utilizado para avaliação da alteração de agregados para construção civil [16]. Para este ensaio é necessário obter as curvas de saturação e secagem das amostras que define qual o tempo mínimo para cada ciclo, ou seja, o tempo de imersão em água e de permanência na estufa. A imersão é feita em um tanque com capacidade de $200 \mathrm{~L}$ preenchido com água destilada e sob condições 

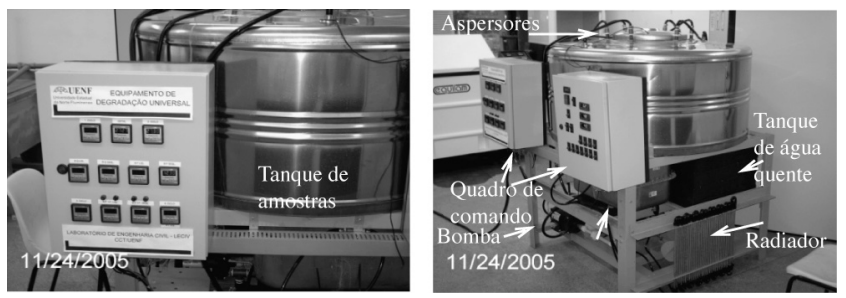

Figura 1: Equipamento de degradação.

[Figure 1: Laboratory weathering device.]

controladas de temperatura. A água foi mantida a $21^{\circ} \mathrm{C}$ com $\mathrm{pH}$ igual 7,0. A secagem foi feita em estufa de laboratório a $110^{\circ} \mathrm{C}$ durante toda a noite. Foram considerados dois níveis de degradação nos ensaios de ciclos de umidade correspondentes a 50 e 150 ciclos.

A avaliação dos efeitos da degradação no material de forma acelerada no laboratório é feita pela análise da variação da absorção, da resistência à flexão e da caracterização microestrutrual do material degradado em relação ao material intacto. $\mathrm{O}$ ensaio de flexão foi de três pontos com distância entre apoios de 9,0 cm e velocidade de carregamento de 0,1 $\mathrm{mm} / \mathrm{min}$. Foi feita para cada condição de degradação uma média de cinco amostras.

Particularmente para a resistência à flexão obteve-se o índice de perda de resistência $\left(\mathrm{I}_{\mathrm{TRF}}\right)$, definido como em função da variação da resistência com o avanço do tempo de degradação (B):

$$
\mathrm{I}_{\mathrm{TRF}}=\frac{\mathrm{TRF}_{\text {intacto }}-\mathrm{TRF}_{\text {degradado }}}{\mathrm{TRF}_{\text {intacto }}} \times 100 \%
$$

A caracterização microestrutrural foi feita por microscopia eletrônica de varredura em um microscópio Zeiss DSM 962.

Deve-se ressaltar que qualquer produto desenvolvido em pesquisa e com aplicabilidade na produção industrial, principalmente de materiais cerâmicos vermelhos utilizados na construção civil, deverá, entre outras características, ter durabilidade face às condições climáticas do ambiente construído.

\section{RESULTADOS E DISCUSSÃO}

\section{Caracterização fïsica}

A Fig. 2 apresenta as curvas de distribuição do tamanho de partículas do resíduo e da massa argilosa.

A distribuição do tamanho de partículas do resíduo de granito é predominantemente constituída de fração silte $(68 \%)$ com partículas entre 0,002 e $0,06 \mathrm{~mm}$. Para a massa argilosa observase a predominância de fração argila (52\%) com partículas inferiores a $0,002 \mathrm{~mm}(2 \mu \mathrm{m})$. Observando a distribuição do tamanho de partícula da massa argilosa e considerando os resultados de $[17,18]$ no estudo de argilas para aplicação em cerâmica, conclui-se que a massa argilosa possui tamanho de partícula adequado para uso em cerâmica vermelha.
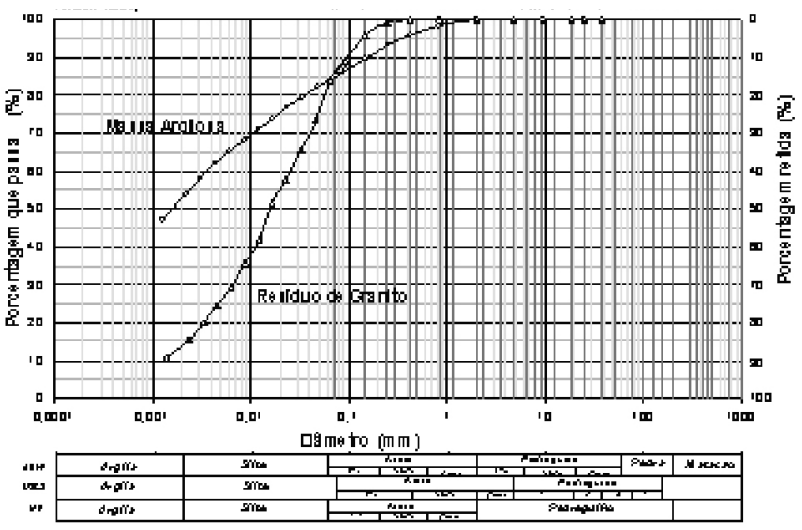

Figura 2: Curvas de distribuição do tamanho de partículas do resíduo e da massa argilosa.

[Figure 2: Particle size distribution curves of clay and waste.]

\section{Caracterização mineralógica}

A Fig. 3 mostra os difratogramas de raios X sobrepostos da massa argilosa e do resíduo de granito e a identificação mineralógica correspondente.

$\mathrm{O}$ difratograma de raios $\mathrm{X}$ do rejeito de granito mostra a presença da mica moscovita $\left(\mathrm{KAl}_{2}\left(\mathrm{AlSi}_{8} \mathrm{O}_{10}\right)(\mathrm{OH})_{2}\right)$ anfibólio, feldspato potássico (microclínico - $\mathrm{KAlSiO}_{8}$ ). Nota-se também a presença de quartzo $\left(\mathrm{SiO}_{2}\right)$ e calcita $\left(\mathrm{CaCO}_{3}\right)$. A calcita pode ser oriunda da poupa abrasiva utilizada no desdobramento do bloco de granito. O difratograma da massa total da argila mostra a presença da ilita, da caulinita $\left(\mathrm{Al}_{2} \mathrm{O}_{3} \cdot 2 \mathrm{SiO}_{2} \cdot 2 \mathrm{H}_{2} \mathrm{O}\right.$ - mineral predominante), da gibsita $\left(\mathrm{Al}(\mathrm{OH})_{3}\right)$ e da goetita $(\mathrm{FeO}(\mathrm{OH}))$.

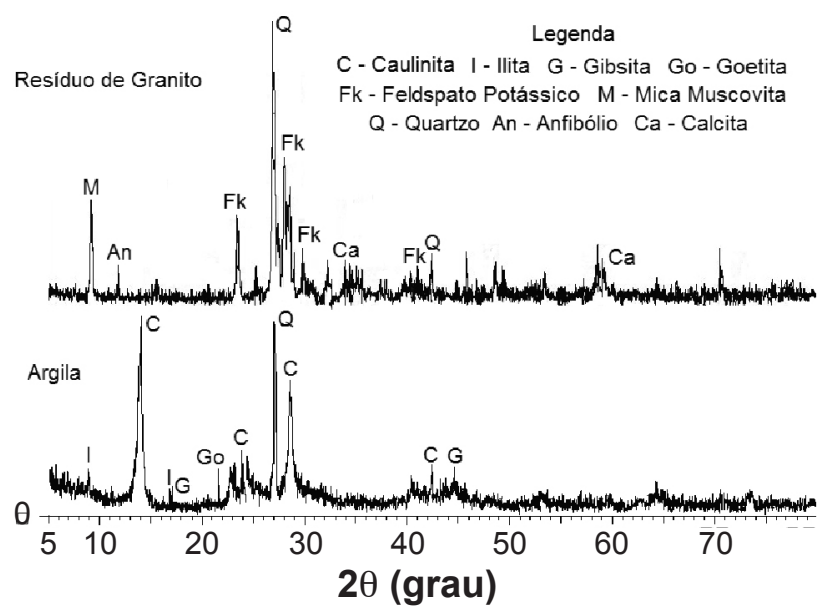

Figura 3: Difratograma de raios $\mathrm{X}$ do resíduo de granito e da argila. [Figure 3: X-ray diffraction patterns of waste and clay.]

\section{Caracterização química}

A Tabela I mostra as composições químicas da massa argilosa e do resíduo de granito. 
Tabela I - Componentes químicos da massa argilosa e do resíduo de granito.

[Table I - Chemical composition of the clay and waste.]

\begin{tabular}{cccccccccc}
\hline Matérias & P.F. & $\mathrm{SiO}_{2}$ & $\mathrm{Al}_{2} \mathrm{O}_{3}$ & $\mathrm{Fe}_{2} \mathrm{O}_{3}$ & $\mathrm{CaO}$ & $\mathrm{MgO}$ & $\mathrm{Na}_{2} \mathrm{O}$ & $\mathrm{K}_{2} \mathrm{O}$ & $\mathrm{TiO}_{2}$ \\
\hline Primas & $(\boldsymbol{\%})$ & $(\boldsymbol{\%})$ & $(\boldsymbol{\%})$ & $(\boldsymbol{\%})$ & $(\boldsymbol{\%})$ & $(\boldsymbol{\%})$ & $(\boldsymbol{\%})$ & $(\boldsymbol{\%})$ & $(\boldsymbol{\%})$ \\
Argila & 15,40 & 42,30 & 32,00 & 6,87 & 0,20 & 0,70 & 0,04 & 0,94 & 1,24 \\
Resíduo Granito & 1,55 & 69,20 & 14,60 & 3,49 & 3,21 & 0,032 & 3,13 & 4,49 & 0,16 \\
\hline
\end{tabular}

A amostra de argila na quantidade de $42,30 \%$ de $\mathrm{SiO}_{2}$ indica a provável presença de argilominerais tais como caulinita $\left(\mathrm{Al}_{2} \mathrm{O}_{3} \cdot 2 \mathrm{SiO}_{2} \cdot 2 \mathrm{H}_{2} \mathrm{O}\right)$ e ilita, bem como a provável presença de quartzo livre na amostra total. A quantidade de $\mathrm{Al}_{2} \mathrm{O}_{3}(32,00 \%)$ apresenta-se quase totalmente formando argilominerais. A alta quantidade de óxido corante $\mathrm{Fe}_{2} \mathrm{O}_{3}(6,87 \%)$ caracteriza-se como indicador da cor vermelha após queima do pó cerâmico. Podese mostrar também a presença de goetita $(\mathrm{FeO} . \mathrm{OH})$. Os álcalis presentes $\left(\mathrm{Na}_{2} \mathrm{O}+\mathrm{K}_{2} \mathrm{O}\right)$ na quantidade de $0,98 \%$ são agentes fundentes, formando fase líquida na queima, reduzindo a porosidade do material. A perda ao fogo (P.F.) de 15,40\%, indica a perda de água livre, adsorvida e de constituição da matériaprima. No resíduo de granito o teor de sílica é superior a $69 \%$ e de $\mathrm{Al}_{2} \mathrm{O}_{3}$ é superior a $14 \%$, indicando tratar de composições químicas de minerais primários (quartzo, feldspato e minerais do grupo da mica). Os teores de $\mathrm{CaO}(3,21 \%)$ e $\mathrm{Fe}_{2} \mathrm{O}_{3}(3,49 \%)$ são provenientes, principalmente, da cal e da granalha utilizadas como lubrificante e abrasivo no processo de desdobramento dos blocos de granito, respectivamente. Os óxidos de sódio e de potássio $\left(\mathrm{Na}_{2} \mathrm{O}+\mathrm{K}_{2} \mathrm{O}\right)$ na quantidade de $7,62 \%$ presentes no resíduo são quase totalmente oriundos do feldspato e da mica e são agentes fundentes, podendo preencher os vazios do cerâmico. A perda ao fogo de $1,55 \%$ do resíduo apresentou pequena perda de massa devido à estabilidade estrutural do resíduo.

\section{Comportamento térmico}

Para avaliação do comportamento térmico, a Fig. 4 mostra as curvas das análises térmicas diferenciais dos materiais estudados.

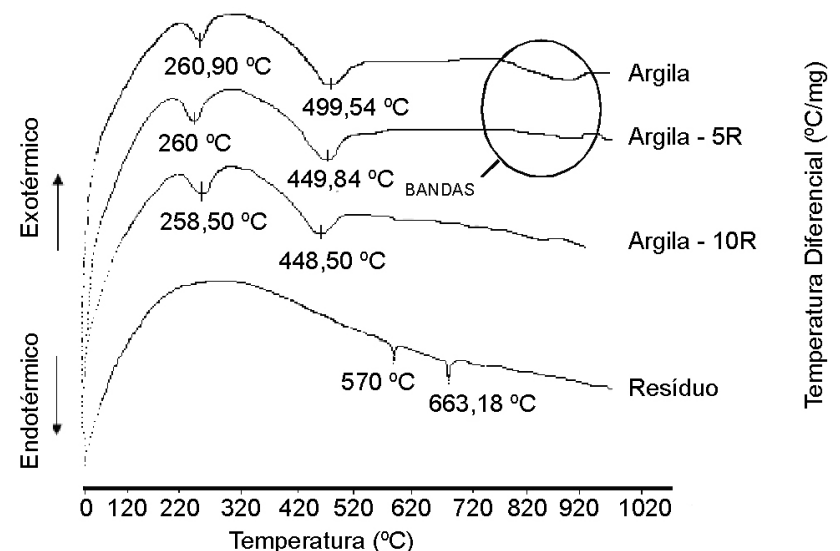

Figura 4: Curvas da análise térmica diferencial (ATD) da massa cerâmica (0R), do resíduo de granito e das misturas 5R e 10R.

[Figure 4: DTA tests on clay and granite waste of $5 R$ and $10 R$ mixtures.]

As curvas térmicas da massa cerâmica e da massa com adição de rejeito com $5 \mathrm{R}$ e $10 \mathrm{R}$ mostram dois eventos endotérmicos de média intensidade próximos. Avaliando as curvas de ATD, verifica-se que a argila $0 R, 5 R$ e $10 R$ apresentam eventos endotérmicos de média intensidade entre $258,50^{\circ} \mathrm{C}$ e $260,90^{\circ} \mathrm{C}$, devido à presença de rejeito na massa cerâmica. Estes picos são devidos à desidroxilação dos hidróxidos de alumínio $\left(\mathrm{Al}(\mathrm{OH})_{3}\right)$ e ferro $(\mathrm{FeO}(\mathrm{OH}))$ devido provavelmente pela presença de gibsita e goetita. Ocorreram eventos endotérmicos de média intensidade entre $448,50{ }^{\circ} \mathrm{C}$ e $499,84{ }^{\circ} \mathrm{C}$ devido ao início da reação de perda de hidroxilas da caulinita, dando origem à sua fase amorfa (metacaulinita). Observam-se bandas endotérmicas a partir

Tabela II - Resultados e condições do ensaio de lixiviação. [Table II - Results and conditions of lixiviation testing.]

\begin{tabular}{cccccc}
\hline $\begin{array}{c}\text { Elemento } \\
\text { químico }\end{array}$ & $\begin{array}{c}\text { Resíduo } \\
\text { Granito } \\
(\mathrm{mg} / \mathrm{L})\end{array}$ & $\begin{array}{c}\text { Limite máximo no } \\
\text { lixiviado MB 2616 } \\
(\mathrm{mg} / \mathrm{L})\end{array}$ & $\begin{array}{c}\text { Condições de } \\
\text { ensaio }\end{array}$ & $\begin{array}{c}\text { Resíduo } \\
\text { Granito } \\
(\mathrm{mg} / \mathrm{L})\end{array}$ & $\begin{array}{c}\text { Limite máximo no } \\
\text { lixiviado MB } 2616 \\
(\mathrm{mg} / \mathrm{L})\end{array}$ \\
\hline $\mathrm{Ag}$ & $<0,005$ & 5,000 & $\mathrm{pH}$ inicial & 9,400 & N.E. \\
$\mathrm{Cd}$ & $<0,002$ & 0,500 & $\begin{array}{c}\text { pH final } \\
\text { Vol. Ácido }\end{array}$ & 5,150 & N.E. \\
$\mathrm{Cr}$ & 0,020 & 5,000 & $\begin{array}{c}(\mathrm{mL}) \\
\mathrm{Tempo}(\mathrm{h})\end{array}$ & 28 & N.E. \\
$\mathrm{Pb}$ & 0,030 & 5,000 & & & N.E. \\
$\mathrm{Ba}$ & 0,110 & 100,000 & & & \\
\hline
\end{tabular}


de $900{ }^{\circ} \mathrm{C}$ podendo indicar a transformação da metacaulinita $\left(\mathrm{Al}_{2} \mathrm{O}_{3} \cdot 2 \mathrm{SiO}_{2} \cdot \mathrm{H}_{2} \mathrm{O}\right)$ amorfa em espinélio $\left(2 \mathrm{Al}_{2} \mathrm{O}_{3} \cdot 3 \mathrm{SiO}_{2}\right)$, formando uma estrutura cristalina estável. A curva correspondente ao resíduo de granito na Fig. 4 apresenta um evento endotérmico de pequena intensidade a $570{ }^{\circ} \mathrm{C}$, indicando a transformação do quartzo $\alpha$ para $\beta$, gerando expansão. Na temperatura de $663,18^{\circ} \mathrm{C}$ verifica-se um pico endotérmico de pequena intensidade correspondente ao início da desidroxilação da mica presente na amostra.

\section{Caracterização ambiental}

Os resultados dos ensaios de lixiviação são apresentados nas Tabelas II e III. Estes ensaios foram realizados devido à presença de granalha no resíduo de granito que funciona como agente abrasivo para desdobramento dos blocos em chapas.

Avaliando os resultados do ensaio de lixiviação e comparando com os limites máximos estabelecidos pela norma [11], observa-se que nenhum dos elementos químicos da massa bruta apresentou concentração acima do máximo recomendado, sendo a amostra considerada não tóxica.

$\mathrm{O} \mathrm{pH}$ do extrato lixiviado da massa bruta está entre 5,15 e 9,4, como variação do estado inicial para o final, caracterizando-se como não corrosivo [11].

Os resultados dos ensaios de solubilização são apresentados na Tabela III.

Avaliando os resultados obtidos nos ensaios de solubilização e comparando com os limites máximos estabelecidos pela norma [11], o elemento químico $\mathrm{Pb}$ da massa bruta solubilizada apresentou concentração

Tabela III - Resultados do ensaio de solubilização.

[Table III - Results of the solubilization tests.]

\begin{tabular}{ccc}
\hline $\begin{array}{c}\text { Elemento } \\
\text { químico }\end{array}$ & $\begin{array}{c}\text { Resíduo } \\
\text { Granito } \\
(\mathrm{mg} / \mathrm{L})\end{array}$ & $\begin{array}{c}\text { Limite máximo } \\
\text { no solubilizado } \\
\text { MB 1067 } \\
(\mathrm{mg} / \mathrm{L})\end{array}$ \\
\hline $\mathrm{Ag}$ & $<0,005$ & 0,050 \\
$\mathrm{Cd}$ & $<0,002$ & 0,005 \\
$\mathrm{Cr}$ & $<0,020$ & 0,050 \\
$\mathrm{~Pb}$ & $<0,060$ & 0,050 \\
$\mathrm{Ba}$ & $<0,020$ & 1,000 \\
$\mathrm{Al}$ & 0,150 & 0,200 \\
$\mathrm{Cu}$ & $<0,010$ & 1,000 \\
$\mathrm{Fe}$ & 0,030 & 0,300 \\
$\mathrm{Mn}$ & $<0,010$ & 0,100 \\
$\mathrm{Zn}$ & $<0,003$ & 5,000 \\
$\mathrm{Na}$ & 33,800 & 200,000 \\
Cloreto & 9,440 & 250,00 \\
Dureza & 19,900 & 500,000 \\
Sulfato & 11,170 & 400,000 \\
\hline
\end{tabular}

ligeiramente superior ao estabelecido no limite máximo devido à presença da granalha de ferro no resíduo de granito. Deste modo, o resíduo classifica-se como classe II, não inerte.

Curva de Saturação $-500^{\circ} \mathrm{C}$
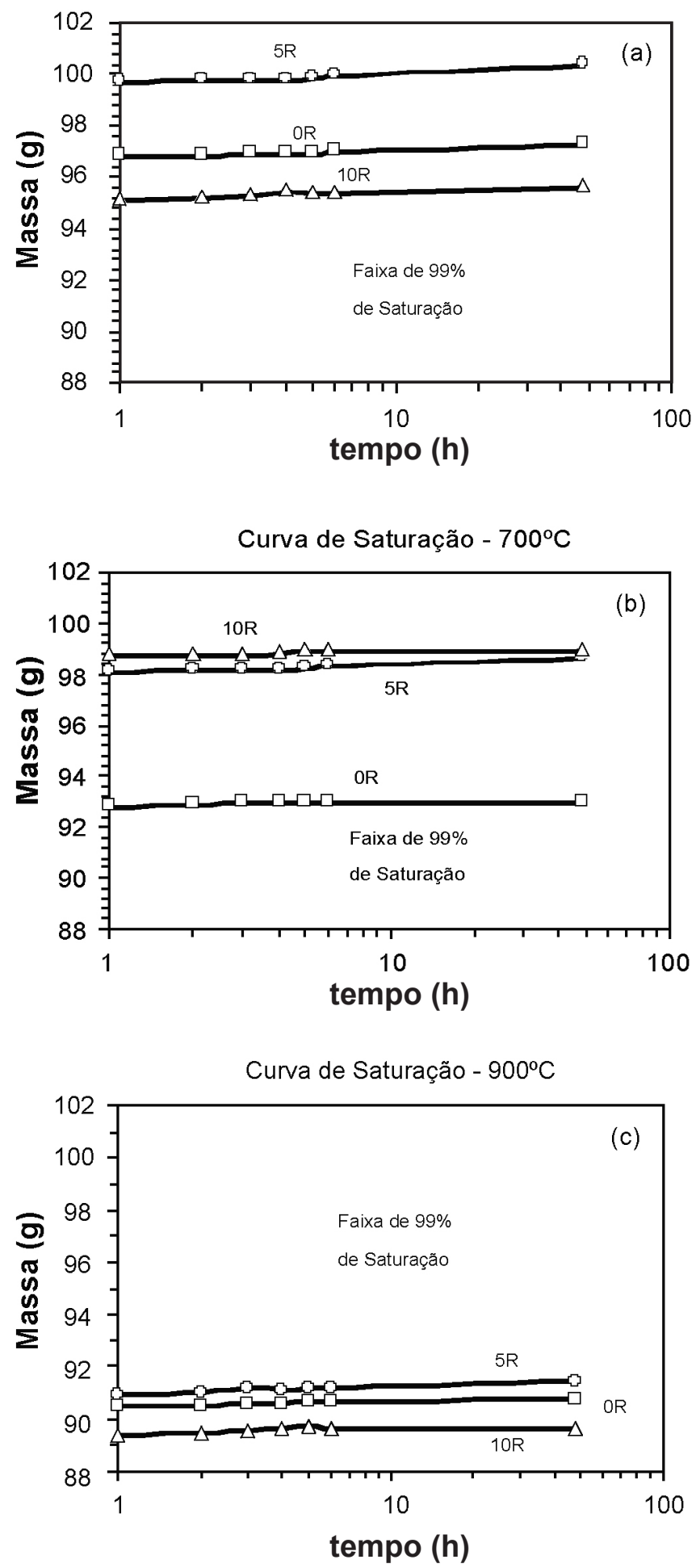

Figura 5: Curvas de saturação para até $48 \mathrm{~h}$ de imersão em água destilada (a-c).

[Figure 5: Saturation curves for up to $48 \mathrm{~h}$ saturation in distilled water.] 
Os resultados obtidos neste trabalho mostraram semelhança com os resultados obtidos por para o rejeito de granito $[19,20]$. Conclui-se então que o rejeito de granito é um material não tóxico, não corrosivo, não inerte de classe II.

\section{Curvas de saturação e secagem}

Considerando que os materiais cerâmicos vermelhos possuem considerável porosidade aberta, normalmente acima de $35 \%$, faz-se necessária a obtenção das curvas de saturação e secagem. Assim, foram essas curvas para cada tipo de amostra, Figs. 5 e 6, respectivamente:

Após $6 \mathrm{~h}$ de saturação ou secagem nota-se a estabilização da umidade dos corpos de prova, independentemente da quantidade de resíduo incorporado. Por questões de logística laboratorial, foram adotados os tempos de 10 e $14 \mathrm{~h}$ para a saturação e secagem, respectivamente, ou seja, um ciclo completo em um dia.

\section{Propriedades tecnológicas}

As Figs. 7 e 8 mostram os resultados da absorção de água e o índice de perda da tensão de ruptura à flexão das peças cerâmicas com adição de resíduo de granito antes (consideradas intactas) e após cada processo de degradação.

\section{Absorção de água}

Para as condições de lixiviação na Fig. 7, o maior efeito da degradação do material foi notado nas amostras com 0R a $700{ }^{\circ} \mathrm{C}$, podendo evidenciar a perda de coesão entre partículas pelo acréscimo de absorção.

Nas amostras queimadas a $900{ }^{\circ} \mathrm{C}$ sob lixiviação contínua, a variação da absorção de água é menor pela maior influência de fase vítrea e maiores mudanças das fases cristalinas presentes nas amostras mantendo-as mais resistentes. A elevação da temperatura de queima também é responsável pela densificação do material cerâmico devido à fusão de alguns óxidos. A fase vítrea se caracteriza pela presença de alcalinos $\left(\mathrm{Na}_{2} \mathrm{O}+\mathrm{K}_{2} \mathrm{O}\right)$ e alcalinos terrosos $(\mathrm{CaO}+\mathrm{MgO})$, que são óxidos fundentes, principalmente quando se adiciona rejeito de granito, conforme observado na Tabela I. Verifica-se na Fig. 7 que os valores da absorção de água para cada adição $0 \mathrm{R}, 5 \mathrm{R}$ e $10 \mathrm{R}$ são semelhantes inclusive à tendência das curvas para a condição de ciclos de umidade e secagem. Nota-se nas curvas de $500{ }^{\circ} \mathrm{C}$ depois de 50 e 150 ciclos um comportamento bastante similar, ocorrendo reduções da absorção de água após 50 ciclos nas amostras com 0R e 10R e nas amostras com 10R após 150 ciclos. As amostras com 5R nesta temperatura apresentam aumento significativo em 50 ciclos. Entretanto, as curvas das amostras queimadas a $900{ }^{\circ} \mathrm{C}$ apresentam a redução de absorção de água após 50 e 150 ciclos quando comparadas com os valores das amostras intactas. Isso se deve a severidade do ensaio, principalmente na secagem em estufa pela tendência de aumento da densidade volumétrica devido a retração do material. O maior efeito
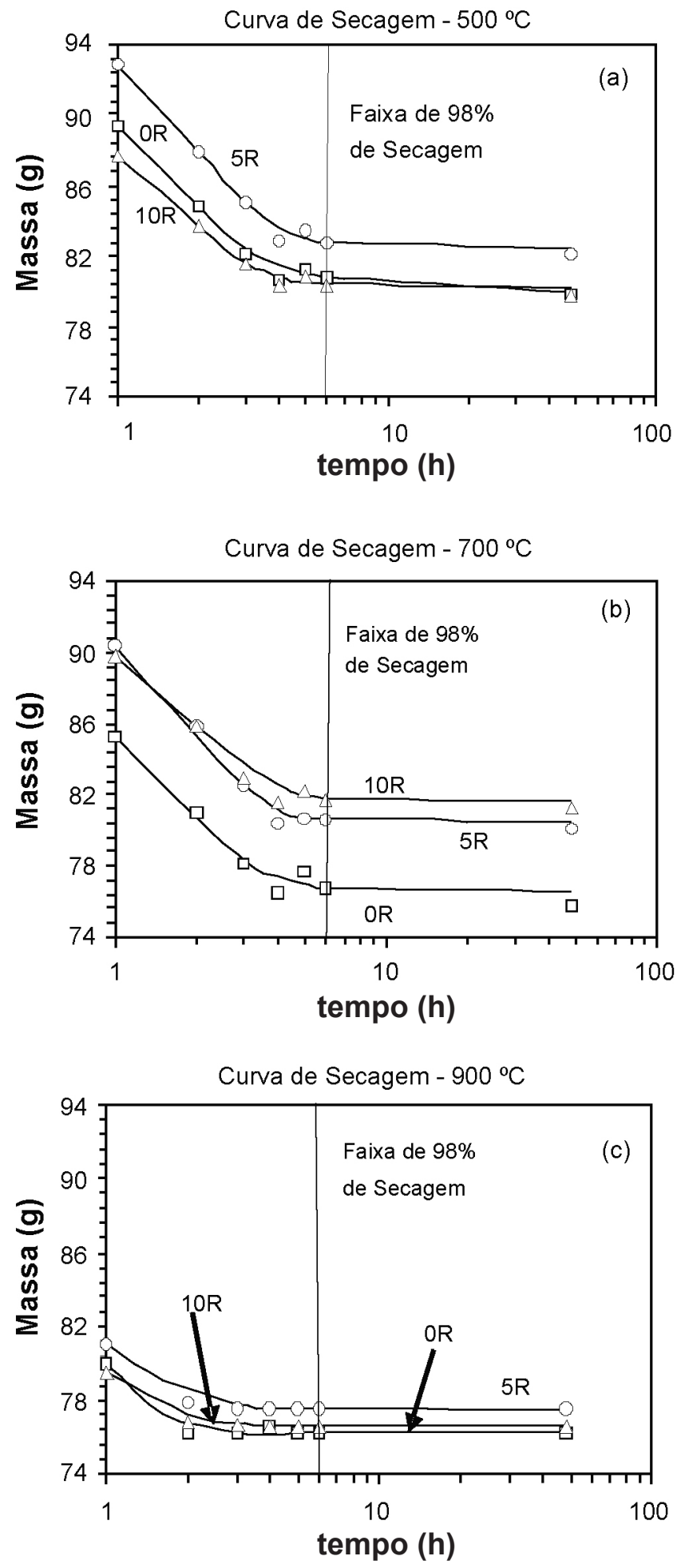

Figura 6: Curvas de secagem de até $48 \mathrm{~h}$ em estufa a $110^{\circ} \mathrm{C}$ (a-c). [Figure 6: Drying curves up to $48 \mathrm{~h}$ in oven at $110^{\circ} \mathrm{C}$.]

da degradação do material evidenciando maior absorção foi notado nas amostras com $0 \mathrm{R}$ a $700{ }^{\circ} \mathrm{C}$ em todas as condições de ciclos de umidade e secagem, devido à perda de massa pela indução da ciclagem na redução de coesão entre partículas. 

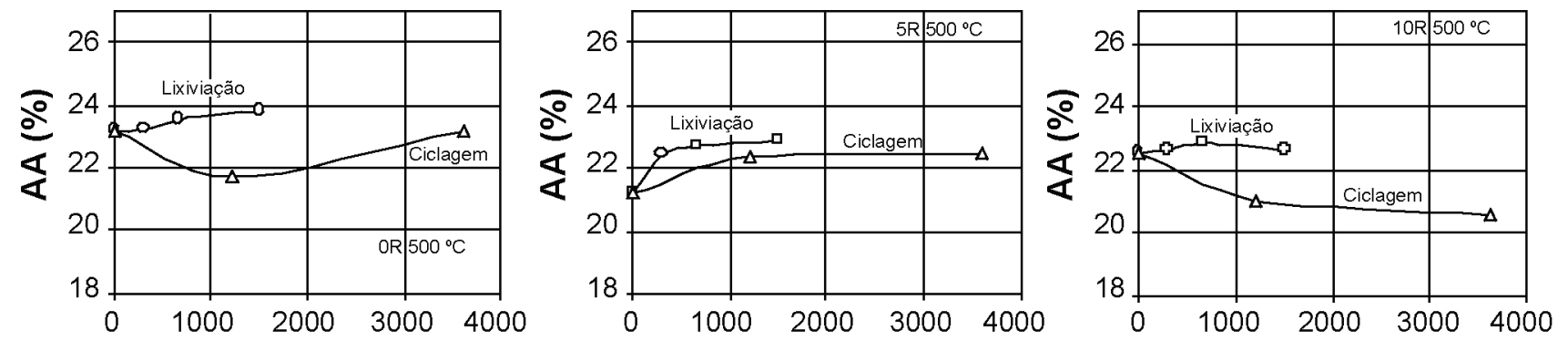

tempo de degradação do lab. (h)
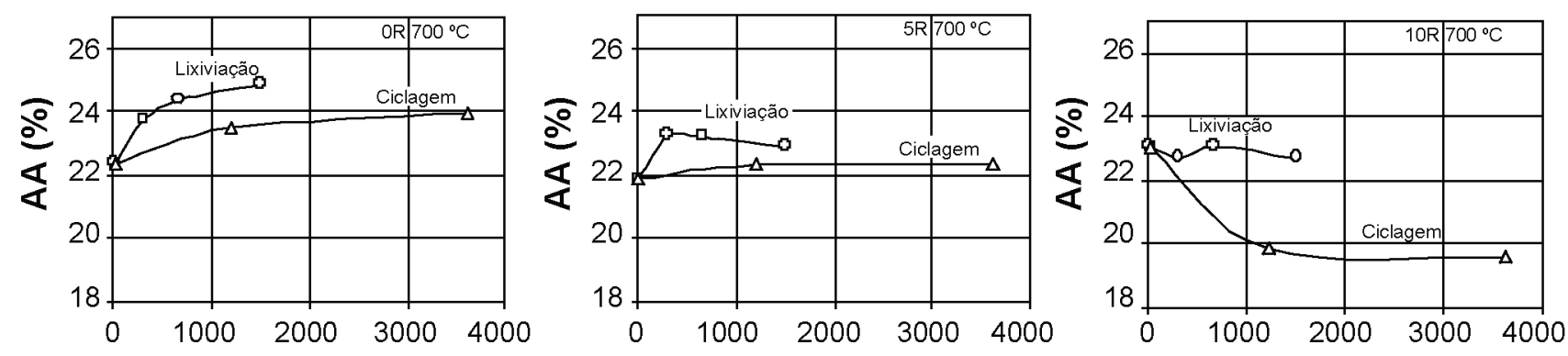

tempo de degradação do lab. (h)
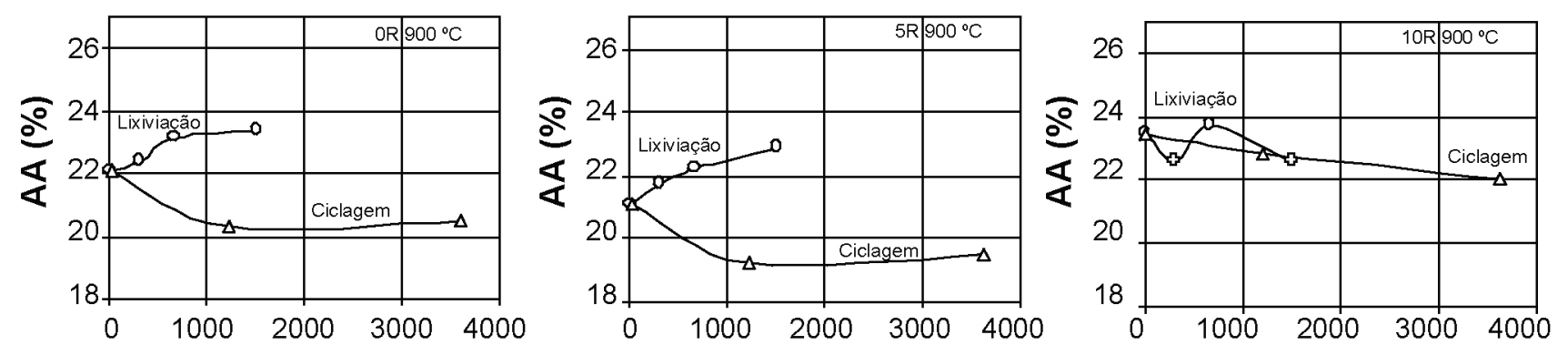

tempo de degradação do lab. (h)

Figura 7: Absorção de água (\%) das amostras consideradas intactas após 300 h, 658 h e 1500 h dentro do equipamento de degradação e 50 e 150 ciclos de secagem e molhagem.

[Figure 7: Water absorption for samples submitted to $300 \mathrm{~h}, 658 \mathrm{~h}$ and $1500 \mathrm{~h}$ of weathering along with 50 and 150 drying-wetting cycles.]

\section{Índice de perda de resistência à flexão}

Avaliando a Fig. 8, verifica-se que a variação do índice $\mathrm{I}_{\mathrm{TRF}}$ com o tempo de degradação é significativamente afetada pelo processo de degradação independente da temperatura de queima ou da adição de rejeito.

Os efeitos da redução de resistência mecânica das peças cerâmicas após a lixiviação contínua foram acentuados para o índice $\mathrm{I}_{\mathrm{TRF}}$ indicados em cada gráfico principalmente a $500{ }^{\circ} \mathrm{C}$ e $700{ }^{\circ} \mathrm{C}$, explicado pelas baixas temperaturas que não são suficientes para maior coalescência entre as partículas. Isso pode ser explicado pelas transformações que ocorrem no estado sólido da massa cerâmica nesta faixa de queima não contribuem significativamente para aumentos da resistência mecânica, conforme observado na Fig. 8.

As amostras indicaram decréscimos de resistências mecânicas semelhantes quando as temperaturas de queima são comparadas, representados por variações muito próximas, inclusive para as de $0 \mathrm{R}$ com relação às de $5 \mathrm{R}$ e 10R, mostrando não indicar diferença no processo de degradação por lixiviação com ou sem adição. O tempo de degradação reduziu a resistência à flexão das amostras sem adição de resíduo a $900^{\circ} \mathrm{C}$ nos primeiros estágios. Nos últimos estágios de degradação, as amostras com adição de rejeito mantiveram-se estáveis, mostrando a eficiência do rejeito como aditivo e não somente como adição na massa de conformação de peças cerâmicas vermelhas. No ensaio de ciclos de umidade e secagem, verifica-se a perda do índice de resistência nas amostras após 50 ciclos e ganhos de resistência após 150 ciclos para a tensão de ruptura à flexão (Fig. 8). As amostras com adição de $5 \mathrm{R}$ revelam maiores resistências mecânicas por apresentarem menores índices 

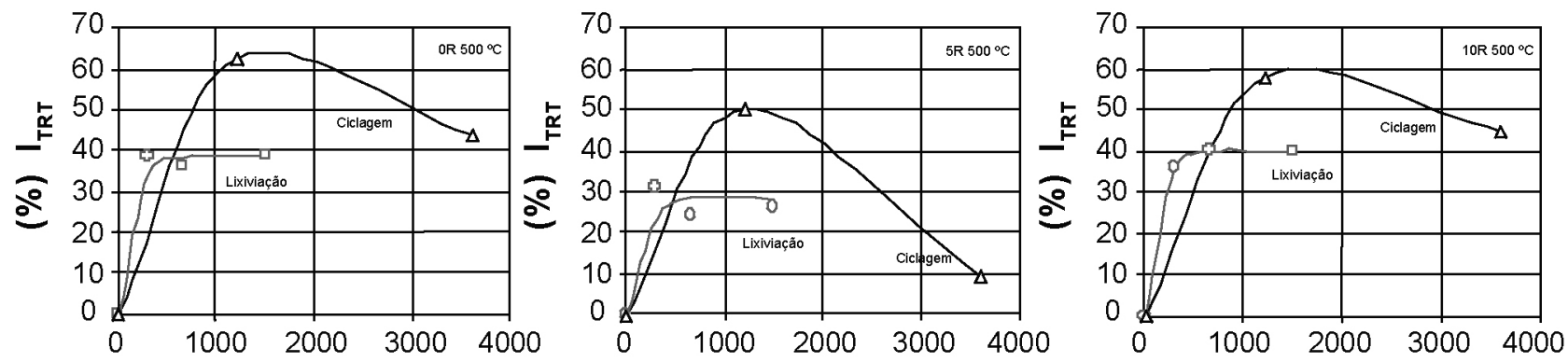

tempo de degradação do lab. (h)
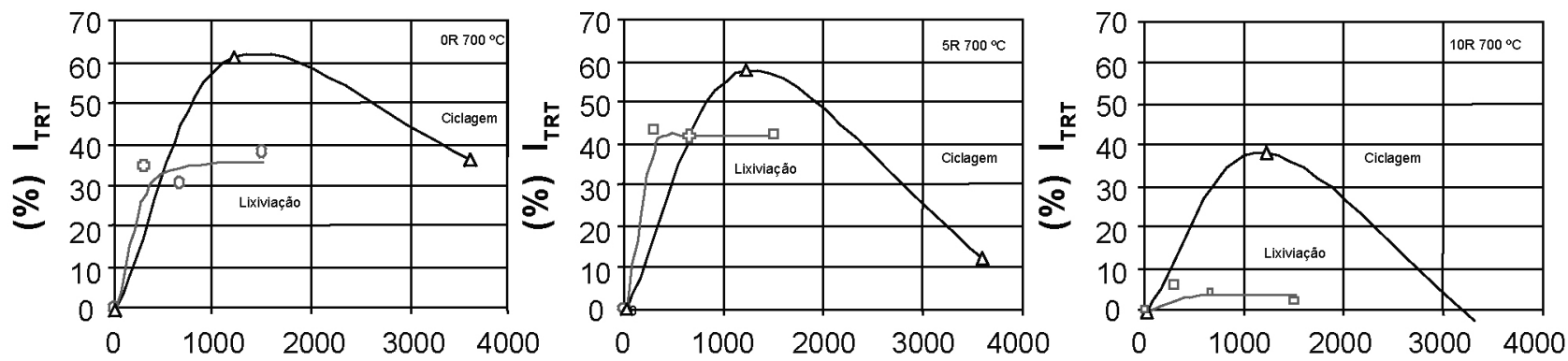

tempo de degradação do lab. (h)
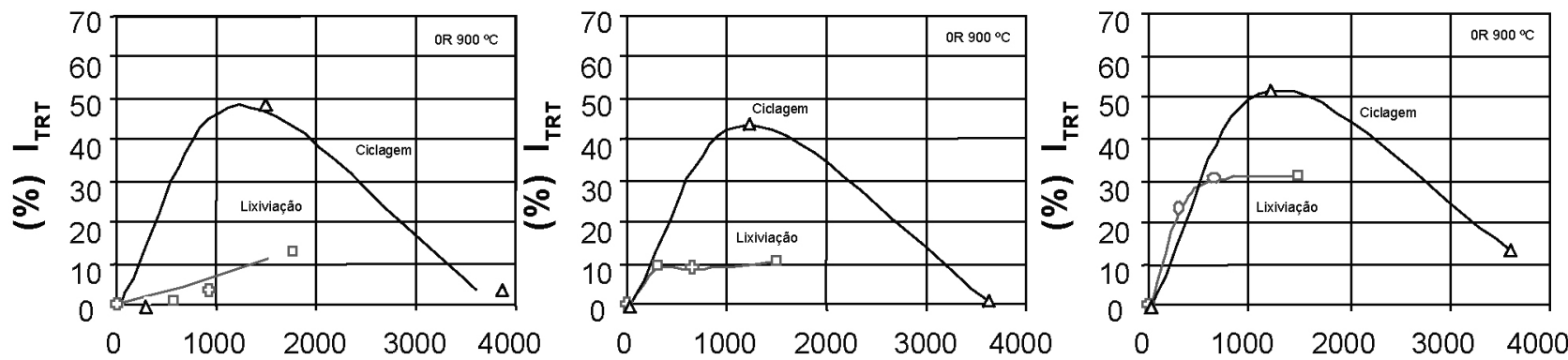

tempo de degradação do lab. (h)

Figura 8: Índice de perda da tensão de ruptura à flexão (\%) das amostras consideradas intactas, e após 300 h, 658 h e 1500 h dentro do equipamento de degradação e 50 e 150 ciclos de secagem e molhagem.

[Figure 8: Loss of flexural strength of samples tested before and after $300 \mathrm{~h}, 658 \mathrm{~h}$ and $1500 \mathrm{~h}$ of weathering and subjected to 50 and 150 wet-drying cycles.]

$\mathrm{I}_{\mathrm{TRF}}$ em todas as temperaturas após o processo de degradação. Para a redução do índice $\mathrm{I}_{\mathrm{TRF}}$ podem ocorrer os processos da sucção e da colmatação concomitantemente. A sucção é a interação de cargas elétricas na superfície de um sólido entre este e o líquido. A litificação ou colmatação é a cimentação de vazios por carbonatos e sais presentes no material. Neste trabalho, espera-se que estes efeitos estejam contribuindo para aumentos de resistência mecânica na ciclagem. Comparando-se as curvas do índice $\mathrm{I}_{\mathrm{TRF}}$, as amostras tendem a um amolecimento em 50 ciclos e posterior enrijecimento com 150 ciclos de umidade e secagem.

\section{Caracterização microestrutural}

Para avaliação da morfologia e textura das amostras intactas e degradadas utilizaram-se as imagens obtidas no microscópio eletrônico de varredura apresentada na Fig. 9. Os ensaios de degradação escolhidos são: lixiviação contínua após $1500 \mathrm{~h}$ e após 150 ciclos de umidade e secagem. As imagens mostradas são aquelas que mais apresentaram defeitos de superfície da amostra após os processos de degradação, ou seja, peças queimadas a $700{ }^{\circ} \mathrm{C}$ sem adição de rejeito (0R).

A Fig. 9a apresenta a imagem no MEV para amostras a $700{ }^{\circ} \mathrm{C}$ intactas. A microestrutura é lisa e existem pequenos poros na superfície do material em relação às Figs. 9b e 9c. Na Fig. 9b a amostra apresentou uma trinca, a textura tornou-se rugosa, com partículas soltas sobre um defeito ou poro de maior dimensão evidenciando a alteração por lixiviação depois de $1500 \mathrm{~h}$ em equipamento de degradação. Na Fig. 9 c a degradação é ainda mais evidenciada nos ciclos de umidade e secagem, trinca e poros são observados, a 

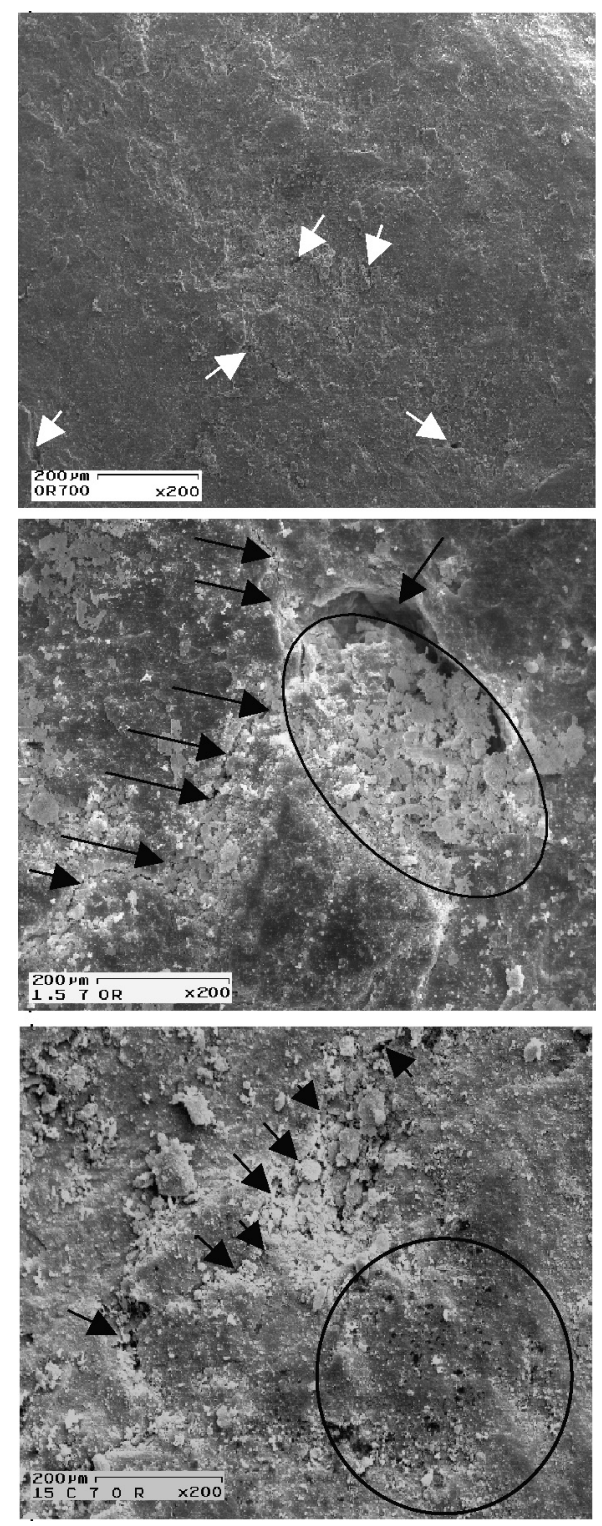

Figura 9: Imagem de microscopia eletrônica de varredura das amostras $0 \mathrm{R}$ a $700{ }^{\circ} \mathrm{C}$ : intacta (a), degradadas por lixiviação contínua (b), e ciclagem (c).

[Figure 9: Scanning electron microscopy images of samples fired at $700{ }^{\circ} \mathrm{C}$ before (a) and after lixiviation (b), and after 150 wetdrying cycles.]

superfície ficou mais rugosa, caracterizando o aumento do índice de $\mathrm{I}_{\mathrm{TRF}}$ da Fig. 8.

\section{CONCLUSÕES}

O resíduo de granito possui partículas de pequenas dimensões ( $66 \%$ de partículas entre 0,002 e $0,06 \mathrm{~mm})$, é uniforme, constituído basicamente de minerais primários e, segundo sua caracterização química, é adequado ao uso para massas cerâmicas. Na análise térmica diferencial o resíduo apresenta-se estável nas temperaturas propostas indicando apenas picos endotérmicos da expansão da areia ou sílica livre a $570{ }^{\circ} \mathrm{C}$ e início da degradação da mica a $663{ }^{\circ} \mathrm{C}$. Na caracterização ambiental do rejeito de granito o material é não tóxico, não corrosivo, não inerte de classe II. A massa argilosa apresentou-se como material adequado ao uso em cerâmica vermelha segundo sua caracterização.

A adição de rejeito de granito gera a redução da absorção de água do material cerâmico vermelho estudado, independente da temperatura de queima e da porcentagem de rejeito, dentro das faixas de temperaturas de queimas e porcentagens de rejeito estudadas.

As características de durabilidade do material estudado não foram determinadas satisfatoriamente através das variações da absorção com o tempo de degradação ou tipo de ensaio de degradação. No entanto, a variação de absorção com o tempo de degradação por lixiviação contínua mostra comportamento preferencialmente crescente. Isto indica que o processo de lixiviação simula adequadamente a tendência de variação, porém, a variação quantitativa das variações não é conclusiva. Como era de se esperar, o processo de lixiviação contínua mostrou a redução da resistência com o tempo de degradação. Tal fato não foi observado nos resultados obtidos nos corpos de prova degradados nos ensaios de ciclos de umidade. Isto indica que a aplicabilidade de ensaios de ciclagem de umidade pode não ser recomendada para a avaliação das características de alteração de materiais cerâmicos, merecendo maiores investigações. No entanto, devido às características do ensaio de ciclagem de umidade, acredita-se que os resultados sejam fortemente influenciados pelo padrão de trincas geradas no processo de fabricação dos corpos de prova por retração na secagem e queima.

Considerando a resistência à flexão para temperaturas de queima de até $700{ }^{\circ} \mathrm{C}$, a incorporação de rejeito de granito pode reduzir as perdas de resistência com o tempo de degradação, melhorando as características de durabilidade. Para temperatura de queima mais elevada, $900^{\circ} \mathrm{C}$, a inclusão de rejeito pode aumentar as perdas de resistência com o tempo de degradação, reduzindo a durabilidade do material.

\section{REFERÊNCIAS}

[1] M. A. Machado, "O setor de rochas ornamentais", "Rejeitos", Palestra apresentada no CREA/ES sobre rejeitos da indústria de rochas ornamentais, Cachoeiro de Itapemirim, ES (2002).

[2] G. C. Xavier, F. A. J. Saboya, P. C. A. Maia, J. Alexandre, Anais do $49^{\circ}$ Congresso Brasileiro de Cerâmica (2005).

[3] R. R. Menezes, R. R. de Almeida, L. N. L. Santana, G. A. Neves, H. L. Lira, H. C. Ferreira, Cerâmica 53, 326 (2007) 192.

[4] H. F. Mothé Filho, H. Polivanov, C. G. Mothé, Anais do $46^{\circ}$ Congresso Brasileiro de Cerâmica (2002).

[5] G. A. Neves, H. C. Ferreira, M. C. Silva, Anais do $44^{\circ}$ Congresso Brasileiro de Cerâmica (2000).

[6] F. A. J. Saboya, G. C. Xavier, J. Alexandre, Construction \& Building Mater. 20 (2007) 1.

[7] C. M. F.Vieira, T. M. Soares, R. Sánchez, S. N. Monteiro, Mater. Sci. Eng. A 373, 1-2 (2004) 115

[8] G. C. Xavier, F. A. J. Saboya, P. C. A. Maia, J. Alexandre. 
Int. Conf. Non-Conventional Mater. and Technol. (2007).

[9] J. M. S. Moreira, M. N. Freire, J. N. F. Holanda, Cerâmica 49, 312 (2004) 262.

[10] Associação Brasileira de Normas Técnicas, Determinação da análise granulométrica dos solos, NBR7181, Rio de Janeiro, RJ (1984).

[11] Associação Brasileira de Normas Técnicas, Resíduos sólidos - Classificação. NBR10004 (1987).

[12] Associação Brasileira de Normas Técnicas, Procedimentos para obtenção de extratos lixiviados de resíduos sólidos, NB 2616 (2004).

[13] Associação Brasileira de Normas Técnicas, Procedimentos para obtenção de extratos solubilizados de resíduos sólidos, NB 1067 (2004).
[14] Associação Brasileira de Normas Técnicas, Amostragem de resíduos sólidos, NB 1068 (2004).

[15] P. C. A. Maia, R. O. Salles, Solos e rochas 1, 1 (2007) 1. [16] P. C. A. Maia, A. D. Pinheiro, J. Alexandre, Mater. Sci. Forum 498-99 (2005) 681.

[17] P. Souza Santos, Tecnologia de Argilas, Ed. Edgard Blucher Ltda., vol. 1 (1989) 499p.

[18] J. Alexandre, Tese de Doutorado em Ciências de Engenharia, UENF (2000) 174p.

[19] R. R. Menezes, H. S. Ferreira, G. A. Neves, H. L. Lira, H. C. Ferreira, J. Eur. Ceram. Soc. 1, 25 (2005) 1149.

[20] J. L. Calmon, F. A. Tristão, F. L. S. Souza, S. C. Silva, F. V. Mattos, Rev. Eng. Ci. Tecnol., Vitória, ES, 3 (1998).

(Rec. 09/01/2008, Rev. 29/02/2008, Ac. 19/06/2008) 